\title{
Evaluation of arterial stiffness in morning hypertension under high-dose valsartan compared to valsartan plus low-dose diuretic
}

\author{
Takeshi Takami
}

Morning hypertension has been reported to be an important risk factor for cardiovascular events, and arterial stiffness bears a relationship with cardiovascular risk. The aim of this study was to evaluate whether high-dose angiotensin II receptor blocker (ARB) treatment has a more beneficial effect on arterial stiffness than regular-dose ARB plus low-dose diuretic treatment in patients with morning hypertension. Forty-three patients, in whom the home systolic blood pressure (BP) in the morning was higher than $140 \mathrm{~mm} \mathrm{Hg}$ and in the evening was lower than $135 \mathrm{~mm} \mathrm{Hg}$, despite treatment with 80 mg valsartan, were randomly assigned to receive $160 \mathrm{mg}$ valsartan (V group, $n=22)$ or $80 \mathrm{mg}$ valsartan plus low-dose trichlormethiazide ( $1 \mathrm{mg})(\mathrm{V}+\mathrm{D}$ group, $n=21)$ for 6 months. There were no differences in the patient background characteristics between the two groups. There were no significant differences in BP measured at home between the two groups. The brachial-ankle pulse wave velocity (baPWV) at the time of diagnosis of morning hypertension was similar in the two groups; however, after 6 months of treatment, a greater degree of reduction of the baPWV and a greater degree of reduction of BP in the supine position were observed in the $V$ group compared with the V+D group. Thus, though both high-dose valsartan and valsartan plus diuretic reduced the BP to a similar degree in patients with morning hypertension, high-dose valsartan exerted a greater beneficial effect on arterial stiffness than did valsartan plus diuretic.

Hypertension Research (2009) 32, 1086-1090; doi:10.1038/hr.2009.156; published online 25 September 2009

Keywords: brachial-ankle pulse wave velocity; diuretics; morning hypertension; valsartan

\section{INTRODUCTION}

On the basis of blood pressure (BP) measurements taken with a BP meter at home and 24-h ambulatory BP monitoring, it has become increasingly clear that casual BP measurements taken in the office setting differ from measurements taken at home; thus, different types of hypertension have come to be described, including white-coat hypertension, masked hypertension and morning hypertension. ${ }^{1}$ As a close association has been reported between BP elevation immediately on awakening in the morning and the onset of cardiovascular disease, ${ }^{2}$ it is expected that novel therapies to control morning hypertension may prevent cardiovascular events.

In addition to early morning hypertension, vascular stiffness has also been pointed out as a risk factor for cardiovascular diseases. ${ }^{3}$ Measurement of the brachial-ankle pulse wave velocity (baPWV) has been reported as a simple method for the determination of vascular stiffness, and this parameter has been reported as an independent predictor of coronary heart disease, including acute coronary syndromes. ${ }^{4,5}$ Thus, measurements of BP and baPWV are useful for evaluation of the risk of cardiovascular events.

Angiotensin II receptor blockers (ARBs) reduce BP in a dosedependent manner and are associated with a low incidence of adverse events, even when used at high doses. ${ }^{6}$ However, guidelines for the treatment of hypertension (JSH2009) recommend the addition of other agents with mechanisms of action that are different from ARBs to obtain improved therapeutic effects. ${ }^{7}$ Thus, a fixed-dose combination of an ARB plus a low-dose diuretic has been used as a useful therapeutic strategy for the treatment of hypertension.

On the basis of these findings, I conducted a comparative evaluation of the effects of treatment with valsartan $(160 \mathrm{mg})$ or valsartan (80 mg) plus low-dose trichlormethiazide ( $1 \mathrm{mg}$ ) on baPWV, as well as on the BP levels measured in the office setting and at home in patients with morning hypertension.

\section{METHODS}

As shown in Figure 1, the study population consisted of hypertensive patients under treatment for at least 3 months at our clinic with $80 \mathrm{mg}$ valsartan once a day, administered after breakfast. Patients diagnosed as having morning hypertension, defined as a systolic BP of $\geqslant 140 \mathrm{~mm} \mathrm{Hg}$ as measured in the morning at home and systolic BP of $<135 \mathrm{~mm} \mathrm{Hg}$ as measured in the evening despite treatment with $80 \mathrm{mg}$ valsartan, were enrolled in this study. The 43 patients who met the eligibility criteria for this study were then randomly allocated to receive either valsartan $(160 \mathrm{mg})$ administered once a day after breakfast 


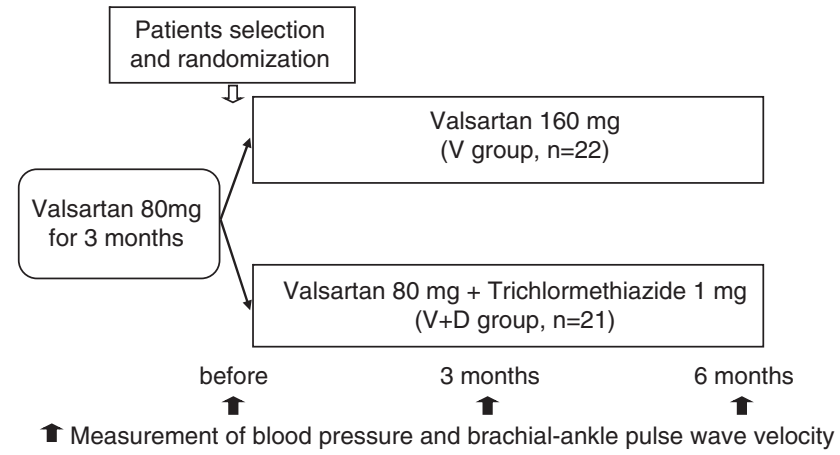

Figure 1 Outline of the study.

(V group; 22 patients) or valsartan $(80 \mathrm{mg})+$ trichlormethiazide $(1 \mathrm{mg})$ administered once a day after breakfast ( $\mathrm{V}+\mathrm{D}$ group; 21 patients). Patients who had secondary hypertension, severe renal dysfunction, congestive heart failure and/or less than 0.9 inch ankle-brachial index (ABI) on both the right and the left side were excluded. To avoid heterogeneity of gender between the two groups, female patients were also excluded. No other antihypertensive agents were used in either group.

In accordance with the guidelines for self-monitoring of $\mathrm{BP}$ at home established by the Japanese Society of Hypertension, patients measured their $\mathrm{BP}$ at home in the morning, within $1 \mathrm{~h}$ of awakening, after evacuating the bladder and after resting for at least 1-2 min in the sitting position, and intake of medication or breakfast. Additionally, patients measured their BP in the evening just before sleeping, after resting for at least $1-2 \mathrm{~min}$ in the sitting position. ${ }^{8}$ In addition to the secondary evaluation parameter of home BP measurement, casual BP was also measured in the office, in the sitting position and BP in the supine position was measured simultaneously with baPWV.

The baPWV, as the primary evaluation parameter, and $\mathrm{ABI}$ were measured at the time of diagnosis of morning hypertension and after 3 and 6 months of treatment with either high-dose valsartan or valsartan plus diuretic. The baPWV and ABI were determined from the pulse waveforms recorded from both forearms and both ankles using the formula PWV/ABI (Omron Healthcare, Kyoto, Japan). These parameters were measured after lying down for at least $5 \mathrm{~min}$ in the supine position. The baPWV and ABI measurements were repeated twice to confirm reproducibility, and the deviation of the two measurements was within $5 \%$. Thus, the mean value on the right side was used as the baPWV value in each patient.

Before the start of the study, written informed consent was obtained from all patients after providing them with an explanation of the contents of this study. The study protocol was approved by the Institutional Ethics Committee.

According to the previous report in which the subtraction of baPWV before and after administration of valsartan $(80 \mathrm{mg})$ was $-195 \mathrm{~cm} \mathrm{~s}^{-1}$, a cohort of 17 patients was determined to be sufficient to detect a difference with an $\alpha$ level of $5 \%$ and a power $(1-\beta)$ of $80 \%$. As few reports have been published on the change in baPWV after treatment with a low-dose diuretic, 40 patients (20 patients for each group) may be more appropriate for a preliminary study.

For the statistical analysis, two-way repeated measures analysis of variance (ANOVA), one-way ANOVA or the $\chi^{2}$ test were performed for inter-group comparisons, and one-way repeated measures ANOVA was performed for intra-group comparisons. Statistical significance was set at $P<0.05$. All individual values were expressed as means \pm standard deviation.

\section{RESULTS}

\section{Patient characteristics}

The study was completed for all of the enrolled patients with no serious adverse events. Table 1 shows the characteristics of the patients at the start of the treatment, when they were all being treated with valsartan $(80 \mathrm{mg})$. Except for the serum level of high-density lipoprotein cholesterol, no differences in the patient background variables were detected between the two groups. In regard to the severity of
Table 1 Patients characteristics

\begin{tabular}{|c|c|c|c|}
\hline & $\begin{array}{l}V \text { group } \\
(\mathrm{n}=22)\end{array}$ & $\begin{array}{c}V+D \text { group } \\
(\mathrm{n}=21)\end{array}$ & P-value \\
\hline Sex (male, \%) & $25(100.0)$ & $21(100.0)$ & - \\
\hline Age (year) & $63 \pm 3$ & $63 \pm 4$ & 0.956 \\
\hline BMI $\left(\mathrm{kg} / \mathrm{m}^{2}\right)$ & $24.8 \pm 0.6$ & $24.7 \pm 0.5$ & 0.565 \\
\hline Current smoker $(n, \%)$ & $7(31.8)$ & $6(28.6)$ & 0.540 \\
\hline $\mathrm{HbA1c}(\%)$ & $5.5 \pm 0.4$ & $5.4 \pm 0.3$ & 0.341 \\
\hline TC (mg per $100 \mathrm{ml}$ ) & $211 \pm 16$ & $214 \pm 9$ & 0.517 \\
\hline HDL-C (mg per $100 \mathrm{ml}$ ) & $53 \pm 7$ & $49 \pm 4$ & 0.024 \\
\hline TG $(\mathrm{mg}$ per $100 \mathrm{ml})$ & $162 \pm 37$ & $158 \pm 36$ & 0.776 \\
\hline UA (mg per $100 \mathrm{ml}$ ) & $5.5 \pm 0.5$ & $5.7 \pm 0.4$ & 0.254 \\
\hline eGFR $\left(\mathrm{ml} \mathrm{min}-1\right.$ per $\left.1.73 \mathrm{~m}^{2}\right)$ & $86.9 \pm 12.0$ & $91.2 \pm 19.0$ & 0.374 \\
\hline SBP in the morning & $146.0 \pm 3.0$ & $145.2 \pm 3.0$ & 0.412 \\
\hline SBP in the evening & $128.3 \pm 3.1$ & $127.1 \pm 3.0$ & 0.200 \\
\hline SBP at the sitting position & $134.2 \pm 3.2$ & $136.5 \pm 1.8$ & 0.016 \\
\hline SBP at the supine position & $154.0 \pm 4.5$ & $153.1 \pm 5.0$ & 0.537 \\
\hline
\end{tabular}

Abbreviations: BMI, body mass index; eGFR, estimated glomerular filtration rate calculated by modified MDRD equation for Japanese population; HbAlc, hemoglobin Alc; HDL-C, high-density lipoprotein cholesterol; SBP, systolic blood pressure; TC, total cholesterol; TG, triglyceride;

$\mathrm{UA}$, uric acid; $\mathrm{V}$ group, valsartan $160 \mathrm{mg}$ group; $\mathrm{V}+\mathrm{D}$ group, valsartan $80 \mathrm{mg}+$ trichlormethiazide $1 \mathrm{mg}$ group. Mean $\pm \mathrm{s}$. $\mathrm{d}$.

hypertension before the start of treatment with valsartan $(80 \mathrm{mg})$ in the study subjects, the systolic BP was in the range of $153-174 \mathrm{~mm} \mathrm{Hg}$ and the diastolic BP was in the range of $83-94 \mathrm{~mm} \mathrm{Hg}(161.5 \pm 5.4 /$ $89.1 \pm 2.9 \mathrm{~mm} \mathrm{Hg}$ in the $\mathrm{V}$ group and $162.5 \pm 4.5 / 89.2 \pm 2.8 \mathrm{~mm} \mathrm{Hg}$ in the $\mathrm{V}+\mathrm{D}$ group). The systolic $\mathrm{BP}$ measured at home was $145.6 \pm 3.0 \mathrm{~mm} \mathrm{Hg}$ in the morning and $127.7 \pm 3.1 \mathrm{~mm} \mathrm{Hg}$ in the evening in all patients, and there were no significant differences between the two groups. These findings indicate that the morning $\mathrm{BP}$ was higher by $17.9 \pm 4.3 \mathrm{~mm} \mathrm{Hg}$ than the evening $\mathrm{BP}$.

\section{Casual and home BP}

In regard to the home $\mathrm{BP}$, significant reduction of both systolic and diastolic BP, including reduction in the normal range of $<135 / 85 \mathrm{~mm} \mathrm{Hg}$ in many patients, was observed after 6 months of treatment in both groups (Figure 2a). A slight, but statistically significant reduction of the evening home BP was also observed (Figure $2 b$ ). These reductions in the BP were similar in the two groups. After 6 months of treatment, the morning systolic BP was $132.6 \pm 3.0 \mathrm{~mm} \mathrm{Hg}$ and the evening systolic BP was $125.8 \pm 2.5 \mathrm{~mm} \mathrm{Hg}$ for all patients in the study. Thus, the difference between the morning and evening systolic BP decreased to $6.8 \pm 3.6 \mathrm{~mm} \mathrm{Hg}$, suggesting that the morning $\mathrm{BP}$ was well controlled in both groups, namely, the high-dose valsartan $(160 \mathrm{mg})$ group and the valsartan $(80 \mathrm{mg})$ plus low-dose diuretic group. Of the 43 patients, the morning systolic BP was controlled to the normal range $(<135 \mathrm{~mm} \mathrm{Hg})$ in 30 patients $(69.8 \%)$, including 15 patients in the $\mathrm{V}$ group and 15 patients in the $\mathrm{V}+\mathrm{D}$ group.

The systolic BP recorded in the supine position was over $140 \mathrm{~mm} \mathrm{Hg}$ before the start of treatment in all patients. Following 6 months of treatment, a significant reduction of both systolic and diastolic BPs measured in the supine position during measurement of the baPWV was also observed in both groups (Figure 3a). A significantly greater reduction of the systolic $\mathrm{BP}$ measured in the supine position was observed in the $\mathrm{V}$ group than in the $\mathrm{V}+\mathrm{D}$ group; the systolic $\mathrm{BP}$ in 11 of 21 patients of the $\mathrm{V}+\mathrm{D}$ group, but not in any of the patients of the $\mathrm{V}$ group, was still over $140 \mathrm{~mm} \mathrm{Hg}$ after 6 months of treatment. However, the systolic and diastolic BPs in the sitting position were not changed significantly in the $\mathrm{V}$ group, and a slight reduction of BP in the sitting position was seen in the $\mathrm{V}+\mathrm{D}$ group (Figure $3 \mathrm{~b}$ ). 

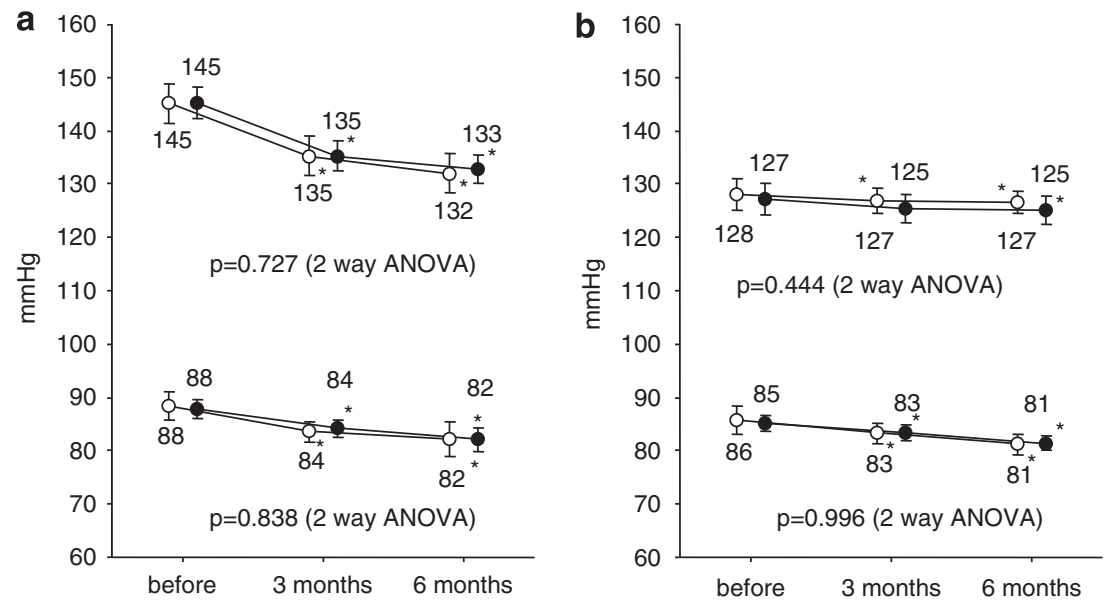

Figure 2 Changes in home blood pressure. (a) In the morning at home, (b) in the evening at home. V group ( $O$ ), valsartan (160 mg) group; V+D group (•), valsartan $(80 \mathrm{mg})+$ trichlormethiazide $(1 \mathrm{mg})$ group; ${ }^{*} P<0.05 \mathrm{vs}$. before treatment. Values indicate the mean of each BP.
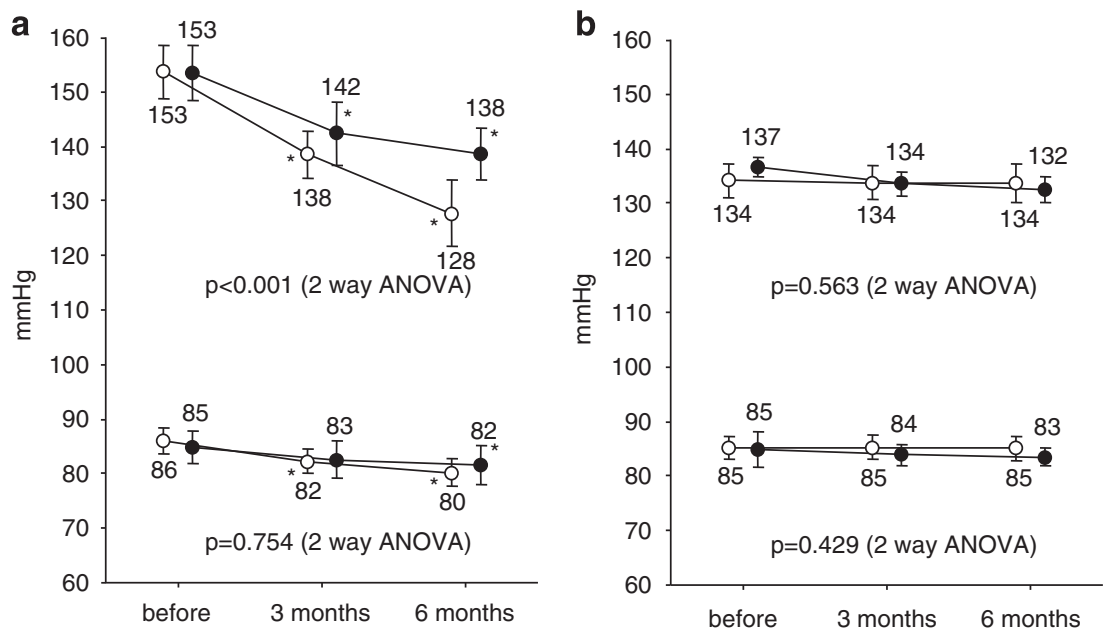

Figure 3 Changes in blood pressure measured in the supine position. (a) in the supine position in the office, (b) in the sitting position in the office. $V$ group $(\mathrm{O})$, valsartan $(160 \mathrm{mg})$ group; $\mathrm{V}+\mathrm{D}$ group $(\bullet)$, valsartan $(80 \mathrm{mg})+$ trichlormethiazide group; ${ }^{*} P<0.05$ vs. before treatment Values indicate the mean of each BP.

\section{baPWV}

Both of the treatment regimens produced a significant and timedependent decrease in the baPWV; however, the decrease in the baPWV was significantly greater in the $\mathrm{V}$ group than in the $\mathrm{V}+\mathrm{D}$ group (Figure 4). A good correlation was observed between the $\Delta$ change of the systolic BP measured in the supine position and the $\Delta$ change of the baPWV in both groups (Figure 5); however, the slope of the single regression was significantly steeper in the $\mathrm{V}$ group than in the $\mathrm{V}+\mathrm{D}$ group. The percent change of the actual baPWV relative to that of the estimated baPWV calculated according to a nomogram ${ }^{10}$ was significantly smaller in the $\mathrm{V}$ group than in the $\mathrm{V}+\mathrm{D}$ group $(0.14 \pm 5.85 \%$ in the $\mathrm{V}$ group, $3.37 \pm 5.82 \%$ in the $\mathrm{V}+\mathrm{D}$ group, $P=0.036)$.

\section{Heart rate and $\mathrm{ABI}$}

No significant changes in the heart rate measured in either the office setting or at home (both morning and evening) were observed in either group, as shown in Table 2. In addition, no significant change in ABI was observed in either group (data not shown). There were no adverse effects related to either the increase in the valsartan dose or the addition of a low-dose diuretic to valsartan $(80 \mathrm{mg})$.

\section{DISCUSSION}

In this study, both valsartan $(160 \mathrm{mg})$, the maximum approved dose of the drug in Japan, and valsartan $(80 \mathrm{mg})$ plus trichlormethiazide (1 mg) produced a significant improvement of systolic and diastolic BP measured at home in patients with morning hypertension. However, high-dose valsartan treatment produced a significantly greater reduction of the baPWV compared with valsartan plus diuretic therapy.

Although recent large-scale clinical studies have shown that the risk of cardiovascular diseases can be reduced by strict BP control, in most studies, casual office BP measurements have been used to evaluate the changes in BP. The guidelines for the treatment of hypertension (JSH2009) also recommend the use of casual office BP measurements to assess the efficacy of BP control. ${ }^{7}$ However, as cardiovascular events frequently occur in the early morning, the increase in BP on awakening that is caused by a physiological pressure reaction is now believed 


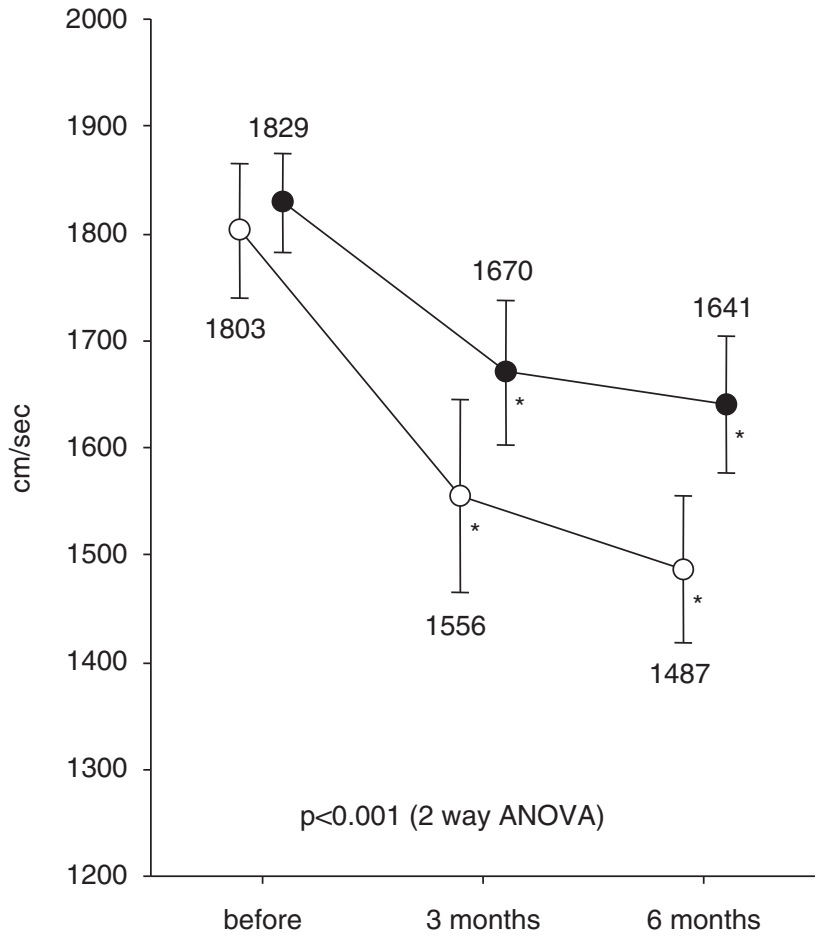

Figure 4 Changes in the brachial-ankle pulse wave velocity (baPWV). $\checkmark$ group $(\bigcirc)$, valsartan $(160 \mathrm{mg})$ group; $V+D$ group $(\bullet)$, valsartan $(80 \mathrm{mg})+$ trichlormethiazide $(1 \mathrm{mg})$ group; ${ }^{*} P<0.05$ vs. before treatment. Values indicate mean baPWV.

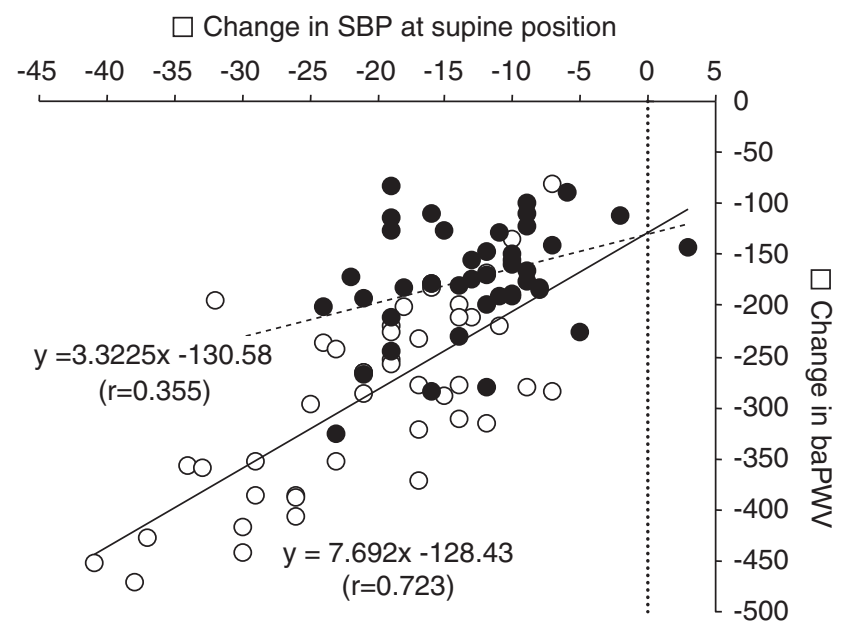

Figure 5 Correlation between the $\Delta$ change in systolic blood pressure (SBP) in the supine position and the $\Delta$ change in brachial-ankle pulse wave velocity (baPWV). V group $(O)$, valsartan $(160 \mathrm{mg})$ group; $\mathrm{V}+\mathrm{D}$ group $(\bullet)$, valsartan $(80 \mathrm{mg})+$ trichlormethiazide $(1 \mathrm{mg})$ group.

to be an important risk factor. ${ }^{11}$ Factors affecting early morning hypertension include early morning activation of sympathetic nervous system activity and activation of the renin-angiotensin-aldosterone system (RAA system), which has reduced activity at night. ${ }^{12}$ Therefore, it is believed that antihypertensive therapy with blockers of the RAA system, such as ARBs, would be useful for the control of early morning hypertension. It has actually been shown that valsartan efficiently reduces BP for an entire day, even when it is administered only on awakening. ${ }^{13}$
Table 2 Changes in heart rate

\begin{tabular}{lcccc}
\hline & Before & 3 months & 6 months & P-value (intra) \\
\hline $\begin{array}{l}\text { Casual } \\
\text { V group }\end{array}$ & $70.4 \pm 4.4$ & $70.3 \pm 4.7$ & $70.2 \pm 4.1$ & 0.958 \\
V+D group & $69.9 \pm 2.7$ & $68.1 \pm 3.6$ & $67.8 \pm 4.0$ & 0.071 \\
& & & & \\
Morning & & & & \\
V group & $66.7 \pm 3.7$ & $65.9 \pm 3.2$ & $66.0 \pm 3.3$ & 0.574 \\
V+D group & $66.1 \pm 2.5$ & $65.6 \pm 2.7$ & $64.9 \pm 2.3$ & 0.186 \\
& & & & \\
Evening & & & & 0.986 \\
V group & $72.4 \pm 2.9$ & $72.4 \pm 2.2$ & $72.3 \pm 2.9$ & 0.118 \\
V+D group & $70.8 \pm 2.0$ & $71.1 \pm 2.8$ & $69.5 \pm 3.3$ & \\
\hline
\end{tabular}

Abbreviations: Intra, intra-group comparison; V group, valsartan $160 \mathrm{mg}$ group; V+D group, valsartan $80 \mathrm{mg}+$ trichlormethiazide $1 \mathrm{mg}$ group.

Morning hypertension was defined on the basis of earlier studies, in which patients with a difference of over $15 \mathrm{~mm} \mathrm{Hg}$ between systolic $\mathrm{BP}$ on awakening in the morning and that measured in the evening were in a higher risk category for cardiovascular diseases, with a higher prevalence of left ventricular hypertrophy and higher serum BNP levels. ${ }^{14,15}$ In this study, although the definition of morning hypertension for enrollment in the study was slightly modified from that in earlier reports, the difference between the systolic BP measured in the morning and that measured in the evening decreased from 17.9 to $6.8 \mathrm{~mm} \mathrm{Hg}$ after treatment in both groups. The results of the study showed that treatment with the maximum dose of valsartan, that is, $160 \mathrm{mg}$, produced an equivalent degree of improvement of the morning BP to that produced by valsartan $(80 \mathrm{mg})$ plus a low-dose diuretic. In patients who satisfied the criteria for morning hypertension described in earlier reports (15 patients in the $\mathrm{V}$ group and 13 patients in the $\mathrm{V}+\mathrm{D}$ group), that is, a home systolic BP of $>135 \mathrm{~mm} \mathrm{Hg}$ (average of the $\mathrm{BP}$ recorded in the morning and evening) with a difference between the morning and evening BP of over $15 \mathrm{~mm} \mathrm{Hg}$, the morning systolic BP decreased from $147.1 \pm 2.1$ to $133.4 \pm 2.6 \mathrm{~mm} \mathrm{Hg}$, and none of the patients showed a value of over $135 \mathrm{~mm} \mathrm{Hg}$ in averaged BP between the morning and evening. These findings indicate that for obtaining satisfactory control of the BP throughout the day, including the morning, blockers of the RAA system or addition of a low-dose diuretic may be recommended.

In regard to the effect of valsartan on baPWV, we reported that valsartan produces the same degree of BP reduction as the angiotensin I converting enzyme inhibitor, temocapril, or the calcium channel blockers cilnidipine or nifedipine, while inducing a significantly greater reduction in baPWV. More specifically, the decrease in baPWV induced by valsartan did not correlate with the effect of the drug on BP. ${ }^{16}$ On the basis of a comparative evaluation of the effect on the baPWV between an ARB and diuretic, it was reported that ARBs induce a BP-independent decrease in aortic stiffness and arterial wave reflection. ${ }^{17}$ In this study, high-dose valsartan $(160 \mathrm{mg})$ produced a greater reduction of the baPWV than valsartan $(80 \mathrm{mg})$ plus a low-dose diuretic, whereas the $\mathrm{BP}$ reduction in the supine position was also significantly larger in the former group than in the latter group. As the existence of a close correlation between baPWV and systolic BP has been reported, ${ }^{18}$ it is believed that the greater reduction of baPWV in the valsartan $(160 \mathrm{mg})$ group was related to the greater reduction of systolic BP measured in the supine position. However, the relationship between the $\Delta$ change of systolic BP and the $\Delta$ change of baPWV shown in Figure 5 indicates that high-dose valsartan produced a reduction of the baPWV that was not proportional to its effect on systolic BP. 
In this study, systolic BP in the supine position increased $19.8 \mathrm{~mm} \mathrm{Hg}$ in the $\mathrm{V}$ group and $16.6 \mathrm{~mm} \mathrm{Hg}$ in the $\mathrm{V}+\mathrm{D}$ group compared with that in the sitting position; however, these increases were reduced after either treatment regimen (see Figures $3 a$ and $b$ ). According to an evaluation of the degree to which arm position influences the measurement of BP in hypertensive patients, the systolic $\mathrm{BP}$ in the supine position was substantially higher than the corresponding BP in the sitting position $(159 \mathrm{~mm} \mathrm{Hg}$ vs. $140 \mathrm{~mm} \mathrm{Hg}$, respectively). ${ }^{19}$ This finding was consistent with observations in this study; however, the precise reasons that the changes in the systolic BP between the two positions were decreased after treatment are not clear. The less dramatic changes in the systolic BP observed in the V group after treatment with a high dose of valsartan may be associated with suppression of sympathetic nerve activity by strict blockage of RAA system despite an unchanged heart rate. ${ }^{20}$

Angiotensin II promotes arterial stiffness by inducing fibrosis, collagen synthesis, smooth muscle cell proliferation and calcification in the arteries. ${ }^{21,22}$ The finding that the differences in baPWV between the measured and estimated value were smaller in the high-dose valsartan group may also indicate that high-dose valsartan exerts a greater beneficial effect on arterial stiffness. These results lend support to the contention that high-dose valsartan has a direct beneficial effect on arterial stiffness, in addition to that exerted through its antihypertensive effect.

It has been reported that baPWV, in the absence of adjustment for age and BP, is well correlated with the Framingham risk score, which is considered the conventional calculator for the risk of coronary heart disease in the general population. ${ }^{23}$ As valsartan suppresses these effects of angiotensin II, its beneficial effects on arterial stiffness shown in this study may contribute to its protective effect against cardiovascular events. Indeed, a recent multicenter, prospective, randomized controlled trial (Jikei Heart Study) showed that valsartan prevents cardiovascular events through a BP-independent mechanism(s). ${ }^{24}$

Taken together, our data suggest a greater degree of RAA system blockage may yield a greater degree of improvement of arteriosclerosis and arterial stiffness, in addition to a potent antihypertensive effect. In terms of vascular protection, valsartan $(160 \mathrm{mg})$ may be a more suitable antihypertensive treatment option for the control of morning hypertension than valsartan $(80 \mathrm{mg})$ plus low-dose diuretic.

These data were presented in part at the 22nd Scientific Meeting of the International Society of Hypertension and the 18th Scientific Meeting of European Society of Hypertension in 2008.

\section{CONFLICT OF INTEREST}

The author declares no conflict of interest.

\section{ACKNOWLEDGEMENTS}

I thank Professor Yoshihiko Saito at First Department of Internal Medicine, Nara Medical University, for his critical suggestions. No grant was used to fund this study.

1 Pickering TG, Eguchi K, Kario K. Masked hypertension: a review. Hypertens Res 2007; 30: 479-488.
2 Björklund K, Lind L, Zethelius B, Andrén B, Lithell H. Isolated ambulatory hypertension predicts cardiovascular morbidity in elderly men. Circulation 2003; 107 : 1297-1302.

3 Blacher J, Guerin AP, Pannier B, Marchais SJ, Safar ME, London GM. Impact of aortic stiffness on survival in end-stage renal disease. Circulation 1999; 99: 2434-2439.

4 Tomiyama H, Koji Y, Yambe M, Shiina K, Motobe K, Yamada J, Shido N, Tanaka N, Chikamori T, Yamashina A. Brachial—ankle pulse wave velocity is a simple and independent predictor of prognosis in patients with acute coronary syndrome. Circ $J$ 2005; 69: 815-822.

5 Yamashina A, Tomiyama H, Takeda K, Tsuda H, Arai T, Hirose K, Koji Y, Hori S, Yamamoto $Y$. Validity, reproducibility, and clinical significance of noninvasive brachialankle pulse wave velocity measurement. Hypertens Res 2002; 25: 359-364.

6 Law MR, Wald NJ, Morris JK, Jordan RE. Value of low dose combination treatment with blood pressure lowering drugs: analysis of 354 randomised trials. Br Med J 2003; 326: 1427-1431.

7 The Japanese Society of Hypertension, Guideline Making Committee for the Management of Hypertension (eds). Guidelines for the Management of Hypertension 2009 (JSH2009). Life Science Publisher: Tokyo, 2009.

8 The Japanese Society of Hypertension, (eds). Guideline for Measurement Conditions of Blood Pressure at Home. Life Science Publisher: Tokyo, 2003.

9 Munakata M, Nagasaki A, Nunokawa T, Sakuma T, Kato H, Yoshinaga K, Toyota T. Effects of valsartan and nifedipine coat-core on systemic arterial stiffness in hypertensive patients. Am J Hypertens 2004; 17: 1050-1055.

10 Yamashina A, Tomiyama H, Arai T, Koji Y, Yambe M, Motobe H, Glunizia Z, Yamamoto Y, Hori S. Nomogram of the relation of brachial-ankle pulse wave velocity with blood pressure. Hypertens Res 2003; 26: 801-806.

11 Bobrie G, Chatellier G, Genes N, Clerson P, Vaur L, Vaisse B, Menard J, Mallion JM. Cardiovascular prognosis of 'masked hypertension' detected by blood pressure selfmeasurement in elderly treated hypertensive patients. JAMA 2004; 291: 1342-1349.

12 Portaluppi F, Bagni B, degli Uberti E, Montanari L, Cavallini R, Trasforini G, Margutti A, Ferlini M, Zanella M, Parti M. Circadian rhythms of atrial natriuretic peptide, renin, aldosterone, cortisol, blood pressure and heart rate in normal and hypertensive subjects. J Hypertens 1990; 8: 85-95.

13 Hermida RC, Calvo C, Ayala DE, Domínguez MJ, Covelo M, Fernández JR, Mojón A, López JE. Administration time-dependent effects of valsartan on ambulatory blood pressure in hypertensive subjects. Hypertension 2003; 42: 283-290.

14 Ishikawa J, Kario K, Hoshide S, Eguchi K, Morinari M, Kaneda R, Umeda Y, Ishikawa S, Kuroda T, Hojo Y, Shimada K. Determinants of exaggerated difference in morning and evening blood pressure measured by self-measured blood pressure monitoring in medicated hypertensive patients: Jichi Morning Hypertension Research (J-MORE) Study. Am J Hypertens 2005; 18: 958-965.

15 Ishikawa J, Hoshide S, Shibasaki S, Matsui Y, Kabutoya T, Eguchi K, Ishikawa S, Pickering TG, Shimada K, Kario K. Relationship between morning hypertension identified by home blood pressure monitoring and brain natriuretic peptide and estimated glomerular filtration rate: the Japan Morning Surge 1 (JMS-1) Study. J Clin Hypertens (Greenwich) 2008; 10: 34-42.

16 Takami T, Shigemasa M. Efficacy of various antihypertensive agents as evaluated by indices of vascular stiffness in elderly hypertensive patients. Hypertens Res 2003; 26: 609-614.

17 Mahmud A, Feely J. Effect of angiotensin II receptor blockade on arterial stiffness: beyond blood pressure reduction. Am J Hypertens 2002; 15: 1092-1095.

18 Tomiyama H, Yamashina A, Arai T, Hirose K, Koji Y, Chikamori T, Hori S, Yamamoto Y, Doba N, Hinohara S. Influences of age and gender on results of noninvasive brachialankle pulse wave velocity measurement-a survey of 12517 subjects. Atherosclerosis 2003; 166: 303-309.

19 Webster J, Newnham D, Petrie JC, Lovell HG. Influence of arm position on measurement of blood pressure. Br Med J 1984; 288: 1574-1575.

20 Kasama S, Toyama T, Kumakura H, Takayama Y, Ichikawa S, Suzuki T, Kurabayashi M. Addition of valsartan to an angiotensin-converting enzyme inhibitor improves cardiac sympathetic nerve activity and left ventricular function in patients with congestive heart failure. J Nucl Med 2003; 44: 884-890.

21 Mahmud A, Feely J. Arterial stiffness and the renin-angiotensin-aldosterone system. $J$ Renin Angiotensin Aldosterone Syst 2004; 5: 102-108.

22 Stergiou GS. Angiotensin receptor blockade in the challenging era of systolic hypertension. J Hum Hypertens 2004; 18: 837-847.

23 Yamashina A, Tomiyama H, Arai T, Hirose K, Koji Y, Hirayama Y, Yamamoto Y, Hori S. Brachial-ankle pulse wave velocity as a marker of atherosclerotic vascular damage and cardiovascular risk. Hypertens Res 2003; 26: 615-622.

24 Mochizuki S, Dahlöf B, Shimizu M, Ikewaki K, Yoshikawa M, Taniguchi I, Ohta M, Yamada T, Ogawa K, Kanae K, Kawai M, Seki S, Okazaki F, Taniguchi M, Yoshida S, Tajima N. for Jikei Heart Study group. Valsartan in a Japanese population with hypertension and other cardiovascular disease (Jikei Heart Study): a randomised, open-label, blinded endpoint morbidity-mortality study. Lancet 2007; 369: 1431-1439. 